\title{
Antimalarial Activity and Isolation of Phenolic Compound from Parkia biglobosa
}

\author{
Modupe Builders $^{1}{ }^{*}$, Taiwo Alemika ${ }^{2}$, John Aguiyi ${ }^{3}$ \\ ${ }^{I}$ Department of Pharmacology and Therapeutics, College of Health Sciences, Bingham University, PMB 005, \\ Karu, \\ ${ }^{2}$ Department of Pharmaceutical chemistry, Faculty of Pharmaceutical Sciences, University of Jos, PMB 2084, \\ ${ }^{3}$ Department of Pharmacology, Faculty of Pharmaceutical Sciences, University of Jos, PMB 2084, Nigeria
}

\begin{abstract}
Parkia biglobosa popularly called African locust bean tree is used traditionally for the treatment of malaria. Phenolic compounds were found to be the major antimalarial components of Parkia biglobosa. The aim of this work is to evaluate the antiplasmodial activity and isolate phenolic compounds from Parkia biglobosa.The stem barks of Parkia biglobosa were extracted with methanol to obtain methanol extract. The extract was also subjected to column chromatography to obtain four fractions, these fractions were preliminary tested for antiplasmodial potency and methanol fraction which gave the most potent effect was fully evaluated and was refractionated to obtain the phenolic compounds. Phytochemical test, Thin layer chromatography (TLC), Infra-red (IR) spectroscopy and functional group tests were used to study the compounds. The compounds showed antimalarial activity against P.berghei and clinical isolate of P.falciparum. This study confirmed the presence of phenolic compounds in the stem extract of Parkia biglobosa, further research is needed to identify the chemical structures of the compounds from Parkia biglobosa and this may serve as new lead structure in the development of an antimalarial agent.
\end{abstract}

Keywords: Phenolic compounds, Parkia biglobosa, Antiplasmodial, Antioxidant, Isolation

\section{Introduction}

Malaria, one of the three most important diseases in Africa according to the World Health Organization (WHO), is a major cause of morbidity and mortality worldwide, especially in developing countries where it has serious economic and social costs [1]. Currently, multi-drug resistance has become one of the most important problems impeding malaria control efforts $[2,3]$. This has led to attempts to discover other antimalarial agents, mainly from plant sources. For decades, Plants from different botanical sources have been used by various traditional medical practitioners (TMPs) for the treatment and cure of malaria [4,5]. For example quinine and artemisinin have been derived from traditional medicine and plant extracts [6].

About $80 \%$ of the populations of many developing countries still use traditional medicines for their health care. Over $90 \%$ of Nigerians in rural areas and about $40 \%$ of the population living in urban areas depend partly or wholly on traditional medicines [7]. Due to economic reasons, most of the people in developing countries are precluded from the luxury of access to modern therapy. This has made the people to rely on plant and animal resources for their health care over centuries [6].

Several studies have been undertaken to evaluate not only the inhibitory effects of various plant extracts on P. falciparum using in vitro culture, but also in vivo anti-malarial properties on Plasmodium berghei-infected mice $[8,9]$.

Parkia biglobosa (Jacq.) R. Br. Ex G. Don popularly known as African locust bean tree is a perennial, deciduous tree common in West African region. Medicines derived from African locust bean tree are of great value to rural communities that cannot afford or do not have access to "modern medicine". In Nigeria, many traditional medicine practitioners have identified the stem bark and leaf of African locust bean tree as a condiment of great value in the treatment of malaria [10]. The stem bark is boiled and taken orally in form of decoction for malaria fever; there are also reports on the use of the bark of Parkia biglobosa, for the treatment of fever in Ghana [4]

The aim of this study is to evaluate the antiplasmodial activity of the phenolic compounds isolated from the stem bark of Parkia biglobosa.

\section{Materials And Methods}

The stem barks of Parkia biglobosa tree were collected in the month of February, 2009 in Chaza village in Niger state of Nigeria. The identification and authentification were done by (Ethno botanist) Mallam Muazam Wudil of department of Medicinal Plant Research and Traditional Medicine of National Institute for Pharmaceutical Research and Development, (NIPRD), Abuja, Nigeria where a voucher specimen (NIPRD /H/6228) was deposited at the herbarium for reference. 


\subsection{Chemicals and reagents}

All chemicals were purchased from Sigma - Aldrich, USA

\subsection{Extraction of plant material}

The air-dried and powdered plant material $(200 \mathrm{~g})$ was extracted with $5 \mathrm{~L}$ methanol for $48 \mathrm{~h}$ using a Soxhlet apparatus (Quicket, UK). The extract was filtered through Whatmann

No. 1 (Whatmann International Ltd, Maidstone, UK) paper and evaporated under reduced pressure using a rotary evaporator to a yield of $20.17 \% \mathrm{w} / \mathrm{w}$ referred as crude extract. The dried extract was stored at $4{ }^{\circ} \mathrm{C}$ until used.

\subsection{Fractionation and isolation}

The fractionation was done as previously described by Builders et al [11]. MF4 was further refractionated using a C-18 silica gel as stationary phase with solvent system Methanol: Water (4:1) of constituent to obtain crude extract of phenol $(4.15 \% \mathrm{w} / \mathrm{w})$.

\subsection{Detection of chemical constituents of phenol extract}

The phenol extract was subjected to qualitative chemical screening for the identification of various classes of chemical constituents using methods described by (5).

\subsection{Thin layer chromatography}

Identification of tannins and flavonoids was further carried out by TLC using pre-coated silica gel $60 \mathrm{GF}{ }_{254}$ Merck plates with different eluting systems (6).

\subsection{Infra-red(IR) spectroscopy}

The IR spectrum was recorded on a Shimadzu FTIR-84000S spectrophotometer.

\subsection{Identification of functional groups}

Functional groups were detected by method of Shriner et al (7).

\subsection{Antioxidant potential}

Ascorbic acid was used as the antioxidant standard and the methanol soluble portion of the phenol compound was extracted and concentrated and used for the antioxidant assessment.

The phenol compound and ascorbic acid at equal concentrations of $0.0313,0.0625,0.1250,0.25,0.5$, and $1 \mathrm{mg} / \mathrm{ml}$ in methanol were prepared. The radical scavenging activities of the extract against 2, 2-Diphenyl1-picryl hydrazyl radical (DPPH) were determined by UV spectrophotometric methods [8]. I ml quantities of the extract and ascorbic acid were placed in a test tube, and $3 \mathrm{ml}$ of methanol added followed by $0.5 \mathrm{ml}$ of $1 \mathrm{mM}$ DPPH in methanol. These were allowed to stand for $30 \mathrm{~min}$ before the absorbance were taken at $517 \mathrm{~nm}$. The blank solution consists of the same amount of methanol and DPPH. The radical scavenging activity presented as percentage inhibition was calculated using equation 1.

$\%$ Inhibition $=[(\underline{\mathrm{Ab}-\mathrm{Aa}}) / \mathrm{Ab}] \times 100 \quad \ldots 1$

Where: $\mathrm{Ab}$ is the absorbance of the blank sample and $\mathrm{Aa}$ is the absorbance of the drug (phenol compound or ascorbic acid).

\subsection{Animals}

As experimental hosts, 6-week-old out bred male (20 $\pm 2 \mathrm{~g})$ and female $(22 \pm 2 \mathrm{~g})$ Swiss albino mice obtained from the animal facility centre of the Department of Pharmacology and Toxicology, National Institute for Pharmaceutical Research and Development (NIPRD), Abuja, Nigeria was used for the study. The animals were housed in standard cages, with standard feed and water given ad libitum, and they were acclimatized for 14 days prior to the experiments. All animal experiments were performed according to Good Laboratory Practice (GLP) regulations [9]. The principle of laboratory animal care [10] was also followed in this study. The LD50 of the compound was determined using male Swiss albino mice by oral route using the method of Lorke et al [11].

\subsubsection{Parasite inoculation}

The malaria parasite used was a chloroquine-sensitive strain of Plasmodium berghei berghei (NK-65), obtained from the National Institute for Medical Research (NIMR), Lagos, Nigeria and kept at the Department of Pharmacology and Toxicology, NIPRD, Idu, Abuja, Nigeria. The parasites were maintained by serial blood passage in mice. Parasitized erythrocytes were obtained from a donor- infected mouse by cardiac puncture in heparin and made up to $20 \mathrm{ml}$ with normal saline. Animals were inoculated intraperitoneally with infected blood 
suspension $(0.2 \mathrm{ml})$ containing $1 \times 10^{7}$ parasitized erythrocytes on day zero. Infected mice with parasitaemia of $5-7 \%$ were allocated to five groups of six mice each (12).

\subsubsection{In vivo antimalarial assay}

A series of experiments were carried out to evaluate the in vivo anti-malarial activities of the phenol compound of African locust bean tree stem bark at 5,10 , and $25 \mathrm{mg} / \mathrm{kg}$ doses as compared to control groups treated with $0.2 \mathrm{ml}$ of normal saline and reference groups treated with standard drugs (Chloroquine diphosphate $25 \mathrm{mg} / \mathrm{kg} /$ day ). Malaria infection was first established in male mice by the intraperitoneal (i.p.) administration of donor male Swiss albino mouse blood containing about $1 \times 10^{7}$ parasites. The three different methods of treating malaria infections, i.e., 4-Day suppressive test, curative and prophylactic methods were applied according to Peters and Robinson [13], Saidu et al [14] and Peters [15] respectively. The laboratory tests were started with oral administrations of the compound in the 4-day suppressive tests (early malaria infection) and further screened for their curative (established malaria infection) and prophylactic (residual malaria infection) activities. Thick blood smears were prepared and blood films were fixed with methanol. The blood films were stained with Giemsa, and then microscopically examined with 100-x magnification. The percentage suppression of parasitaemia was calculated for each dose level by comparing the parasitaemia in infected controls with those of treated mice [16].

\subsubsection{In vitro antimalarial assay}

2.9.3.1.Patients' selection

Three fresh blood specimens were collected from three patients suffering from fever and other malaria symptoms with confirmed infection by P. falciparum. Already prepared dried -in-acridine orange -stained thin smears were examined for Plasmodium species identification. The parasite density was determined by counting the number of infected erythrocytes among 20,000 erythrocytes from each patient, $4 \mathrm{ml}$ of venous blood was collected in a tube coated with EDTA. Samples with monoinfection due to Plasmodium falciparum and a parasite density between 1 and $2 \%$ were used for the in vitro antimalarial tests [17].

\subsubsection{In vitro test}

The assay was performed in duplicate in a 96-wellmicrotiter plate, according to WHO method in vitro micro test (Mark III) [16]. RPMI 1640 (Sigma Company, USA) was the culture medium used for cultivation of P. falciparum [17]. Dilutions were prepared from the phenol compound and the final concentrations prepared by dilution were $(5,1,0.5,0.2,0.1$ and $0.05 \mu \mathrm{g} / \mathrm{ml})$. Negative controls were treated with solvent and positive controls (Chloroquine phosphate) were added to each set of experiments. Fifty microliters from blood mixture media was added to each well in plate and incubated in a candle jar (with gas environment of about 3\% O2, 6\% $\mathrm{CO} 2$ and $91 \% \mathrm{~N} 2$ ) [18] at $37.0^{\circ} \mathrm{C}$ for $24-30 \mathrm{~h}$. After incubation, contents of the wells were harvested and stained for $5 \mathrm{~min}$ in an already prepared dried -in-acridine orange reagent. The parasites were counted in five fields of vision (> 200 total cells) using a fluorescence microscope (Partec cyscope fluorescence microscope, Germany) at a magnification of 40 .

\subsubsection{Data analysis}

Data were expressed as the mean \pm standard error of mean (SEM). The Student's t-test and ANOVA (one- or two-way) were used to test the differences between groups. Differences between means at $5 \%$ level $(\mathrm{P} \leq 0.05)$ were considered significant. The IC 50 values were determined graphically on a log doseresponse curve (log concentration versus percent inhibition curves) by interpolation while those values for the antioxidant activities were calculated from the linear regression of plots of concentration of the test compounds $(\mathrm{mg} / \mathrm{ml})$ against the percentage of inhibition of 2, 2-Diphenyl-1-picryl hydrazyl.

\subsection{Phytochemical test}

\section{Results}

Phytochemical screening of the phenol extract of P.biglobosa revealed the presence of tannins and phenols. Alkaloids, carbohydrate, saponins, flavonoids, terpenes, glycosides and sterols were not detected (Table 1).

Table 1: Phytochemical screening of phenol extract of P.biglobosa stem bark

\begin{tabular}{|l|l|}
\hline Phytochemicals & Remarks \\
\hline Alkaloids & - \\
\hline Carbohydrates & - \\
\hline Saponins & - \\
\hline Flavonoids & - \\
\hline Terpenes & - \\
\hline
\end{tabular}




\begin{tabular}{|l|l|}
\hline Tannins & + \\
\hline Glycosides & - \\
\hline Phenols & + \\
\hline Sterols & - \\
\hline
\end{tabular}

$+=$ Present; $-=$ Absent

\subsection{Thin layer chromatography}

The presence of tannins and phenols was confirmed by thin layer chromatography. Six compounds were separated with $R_{f}$ values ranging from 0.88 to 0.97 , two of the compounds had similar $R_{f}$ values with the standards. Formation of brown spots with $\mathrm{I}_{2}$ vapour indicated the presence of organic compounds and the appearance of bluish green spots with ferric chloride showed the presence of phenolic compounds (Table 2).

Table 2: TLC screening of phenol extract of P.biglobosa stem bark

\begin{tabular}{|l|l|l|l|l|l|}
\hline Drugs & Daylight & UV lamp & $\mathrm{I}_{2}$ Vapour & Fecl $_{3}(1 \%)$ & $\mathrm{R}_{\mathrm{f}}$ values \\
\hline Tannins & Non -visible & Orange spot & Brown & Bluish-green & $0.88,0.92,0.97$ \\
\hline Phenols & " & " & " & & $0.78,0.84,0.95$ \\
\hline Catechin & " & " & ", & " & 0.97 \\
\hline Gallic acid & ", & & & 0.78 \\
\end{tabular}

\subsection{IR spectroscopy}

In the IR spectrum analysis the phenol extract showed strong absorption between 3200 and $3600 \mathrm{~cm}^{-1}$, indicating carboxylic hydroxyl function. Absorption between 2500 and $3000 \mathrm{~cm}^{-1}$ were considered as hydroxyl function. Maximum absorption peaks of $\mathrm{CH}$ function appeared at $2900 \mathrm{~cm}^{-1}$. Other absorptions include 1688 $\mathrm{cm}^{-1}$ indicative of the presence of carbonyl group $(\mathrm{C}=\mathrm{O})$ which is the carboxylic carbonyl, 1610 and $1527 \mathrm{~cm}^{-1}$ indicative of $\mathrm{C}=\mathrm{C}$ from aromatic ring. Absorptions at $1449 \mathrm{~cm}^{-1}$ are indicative of $\mathrm{C}-\mathrm{H}$ bending. The absorptions between 1034 and $1220 \mathrm{~cm}^{-1}$ are due to C-O stretching from the carboxylate groups, while absorptions from 680 to $850 \mathrm{~cm}^{-1}$ are indicative of the phenyl ring substitution (Figure1 and Table 3).

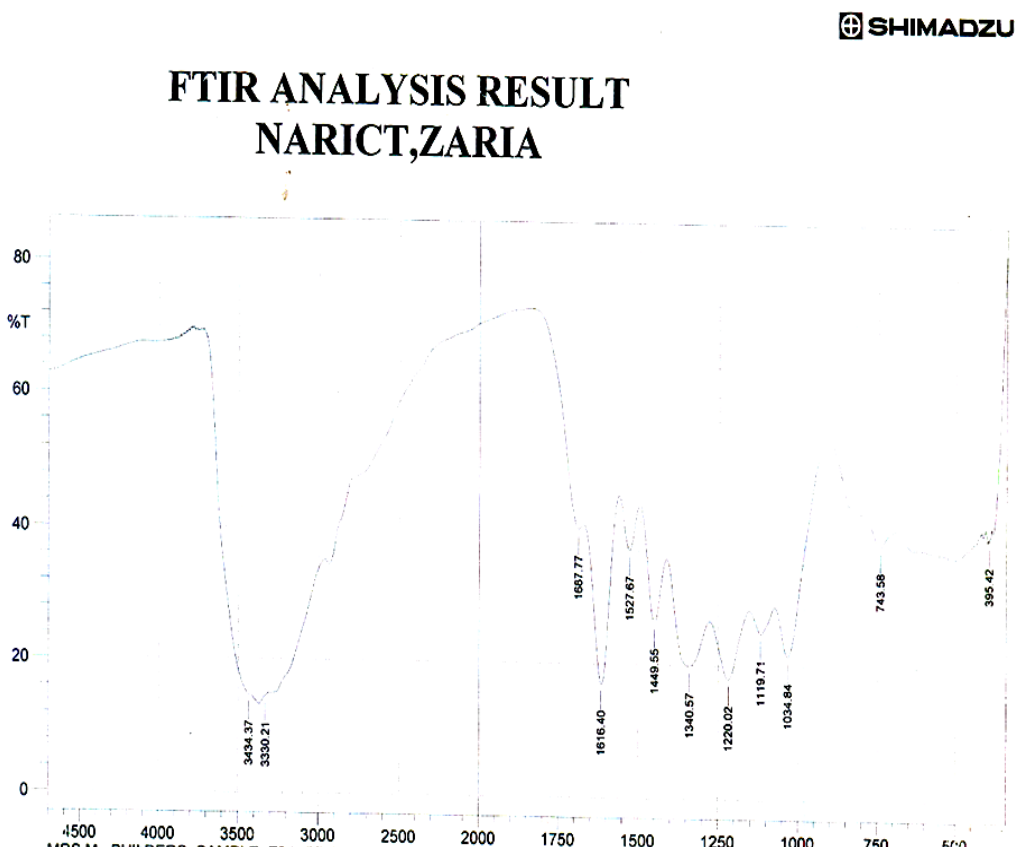

Figure 1: IR spectrum of Phenol extract

Table 3: IR spectroscopy of phenol extract of P.biglobosa tree stem bark

\begin{tabular}{|l|l|}
\hline Bonds & FT-IR frequencies $\left(\mathrm{cm}^{-1}\right)$ \\
\hline $\mathrm{O}-\mathrm{H}(\mathrm{COOH})$ & $3200-3600$ \\
\hline $\mathrm{O}-\mathrm{H}($ alcohol $)$ & $2500-3000$ \\
\hline $\mathrm{C}-\mathrm{H}$ & 2900 \\
\hline $\mathrm{C}=\mathrm{O}$ & 1688 \\
\hline $\mathrm{C}=\mathrm{C}$ & $1527-1610$ \\
\hline $\mathrm{C}-\mathrm{O}$ & $1034-1220$ \\
\hline $\mathrm{C}_{6} \mathrm{H}_{5}$ & $680-850$ \\
\hline
\end{tabular}




\subsection{Functional group tests}

Results of functional group tests indicated the presence of phenolic rings, double bonds and aldehyde/ketone groups (Table 4).

Table 4: Functional Groups of phenol extract of African locust bean tree stem bark

$+=$ Present; - = Absent

\begin{tabular}{|l|l|}
\hline Functional Group & Remarks \\
\hline Phenol & + \\
\hline Double bond & + \\
\hline Aldehyde/ketone & + \\
\hline
\end{tabular}

\subsection{Acute toxicity test}

Doses above $500 \mathrm{mg} / \mathrm{kg}$ were safe and devoid of any adverse clinical symptoms, The $\mathrm{LD}_{50}$ was calculated to be $>500 \mathrm{mg} / \mathrm{kg}$ P.O.

\subsection{In vivo antiplasmodial activity of phenol extract}

The photomicrograph of the in vivo antiplasmodial activity of the phenol extract is presented in (Figure 2).
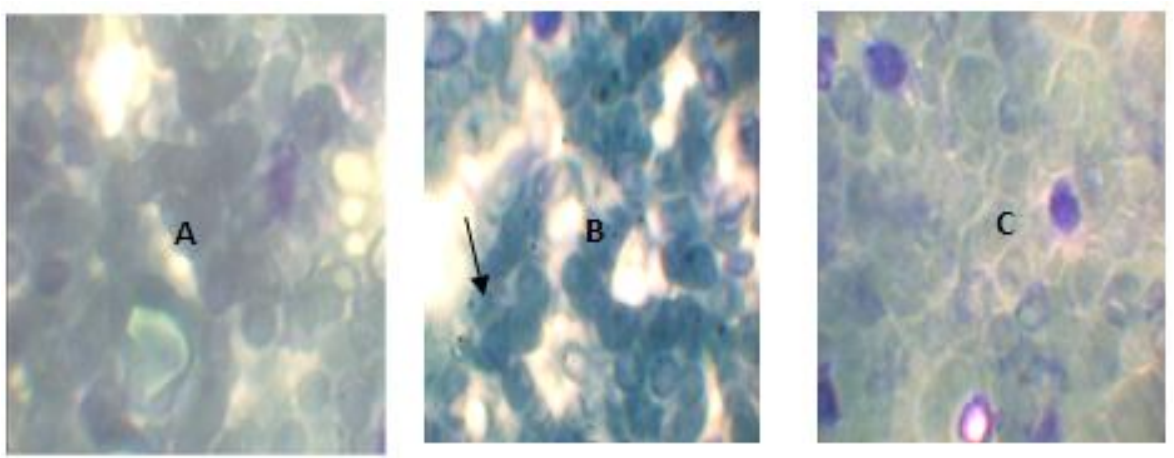

Figure 2: Photomicrographs of in vivo antiplasmodial study.

A: Slide showing no P. berghei berghei in blood smear of uninfected mouse. B: Slide showing P.berghei berghei (black arrow) in blood smear of infected mouse. C: Slide showing no P.berghei berghei in blood smear of treated mouse. (x 100 magnifications).

Phenol extract dose-dependently reduced the mean parasitic count in suppressive, curative and prophylactic antiplasmodial study. Chloroquine also exhibited a similar antiplasmodial activity (Figure 3).

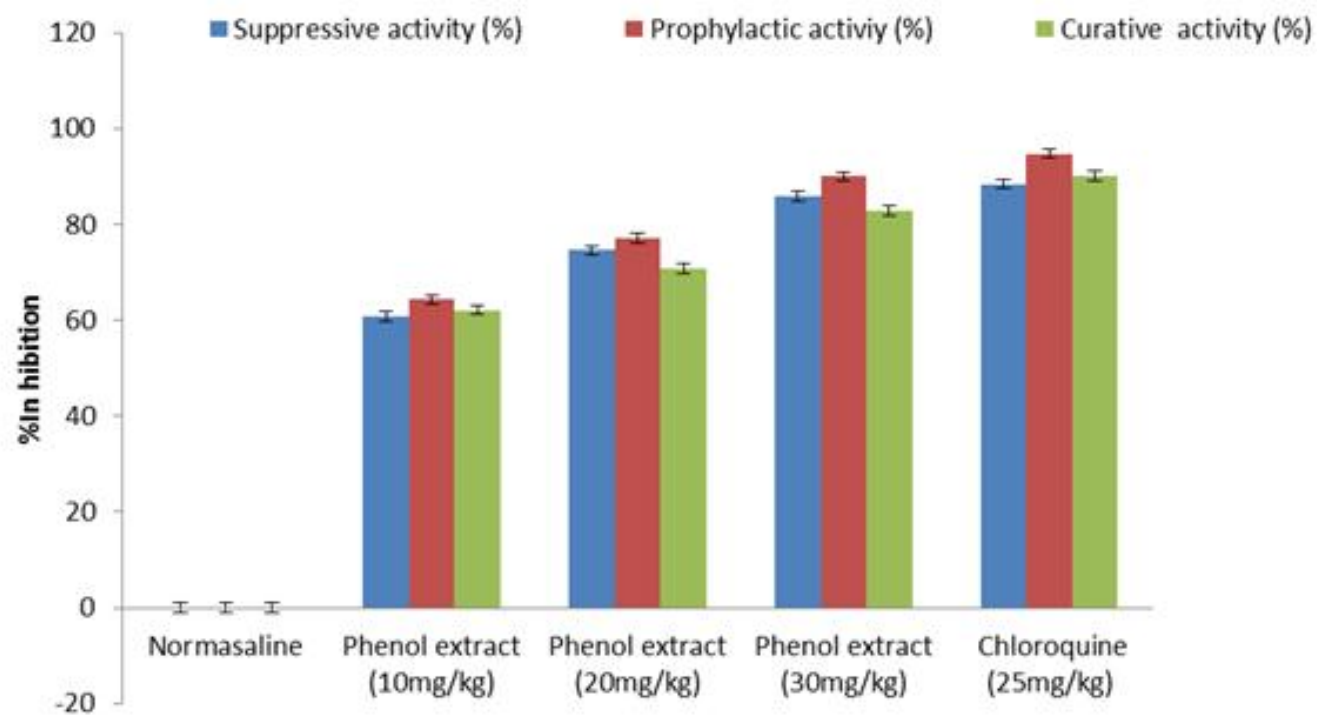

Figure 3: In vivo Antiplasmodial activity of phenol extract of P.biglobosa 
3.6.1. In vitro antiplasmodial activity of the phenol extract

The photomicrograph of the in vitro antiplasmodial activity of the phenol extract is presented in (Figure 4).
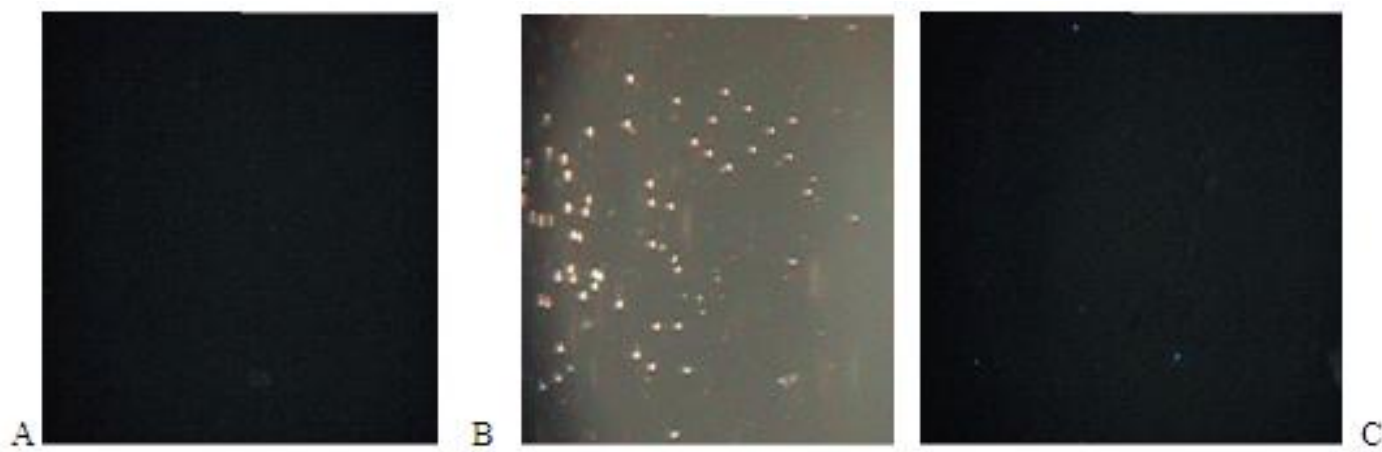

Figure 4: Photomicrographs of the in vitro antiplasmodial activities of the phenol extract.

A. Complete RPMI medium B. Untreated RPMI medium with P.falciparum C. RPMI medium treated with phenol extract

The compound showed a significant concentration dependent growth inhibition of $\mathrm{P}$. falciparum, the $\mathrm{IC}_{50}$ of the phenol extract of P. biglobosa was determined as $0.51 \mu \mathrm{g} / \mathrm{ml}$. Maximum plasmodia inhibition of 79.2 $\pm 1.2 \%$ for the phenol extract and $98.8 \pm 1.4 \%$ for artemisinin at a concentration of $1 \mu \mathrm{g} / \mathrm{ml}$ (figure 5).

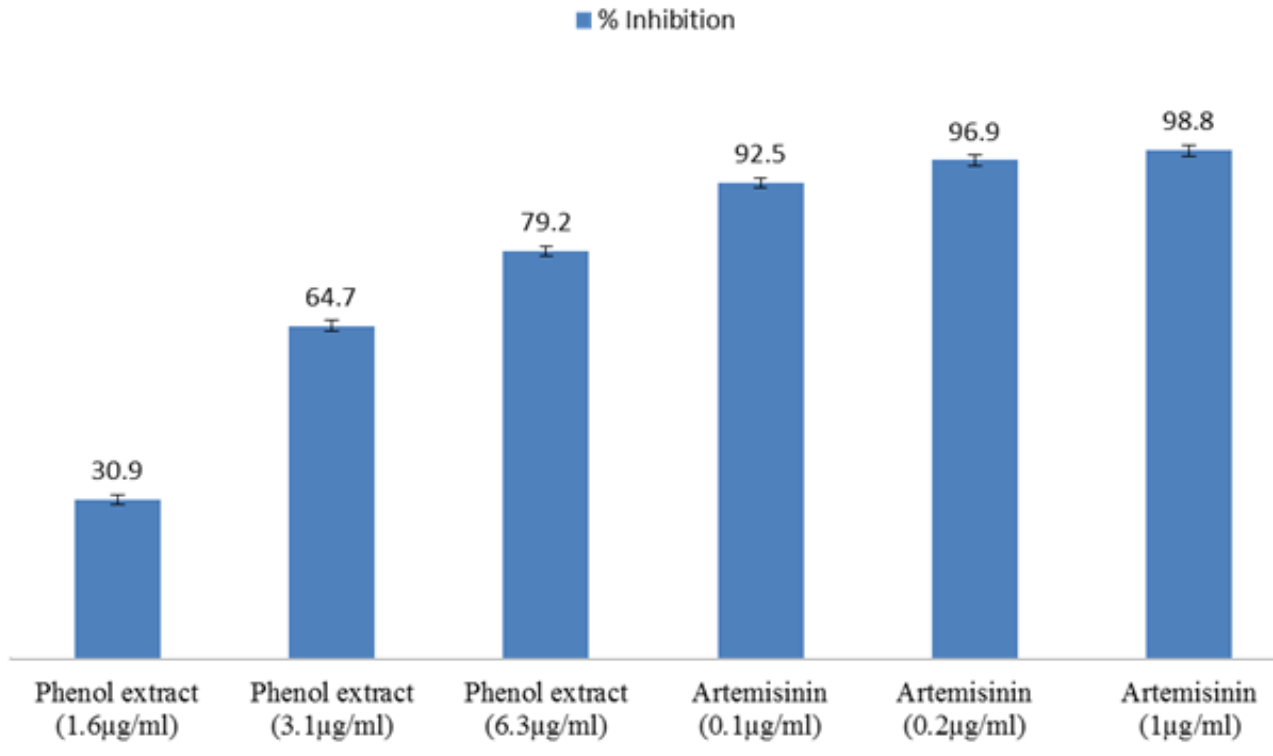

Figure 5: In vitro antiplasmodial activity of phenol extract

\subsection{Antioxidant activity}

The antioxidant activities of phenol extract and ascorbic acid increased with increase in concentration. The phenol extract and ascorbic acid showed maximum DPPH radical scavenging activity of 97.03 and $97.43 \%$. Phenol extract exhibited strong free radical scavenging activity at all concentrations from $(0.0313-1 \mathrm{mg} / \mathrm{ml}) \mathrm{with}$ inhibition of (90.44 -97.43\%), similar inhibition was observed with ascorbic acid (Fig.6). 


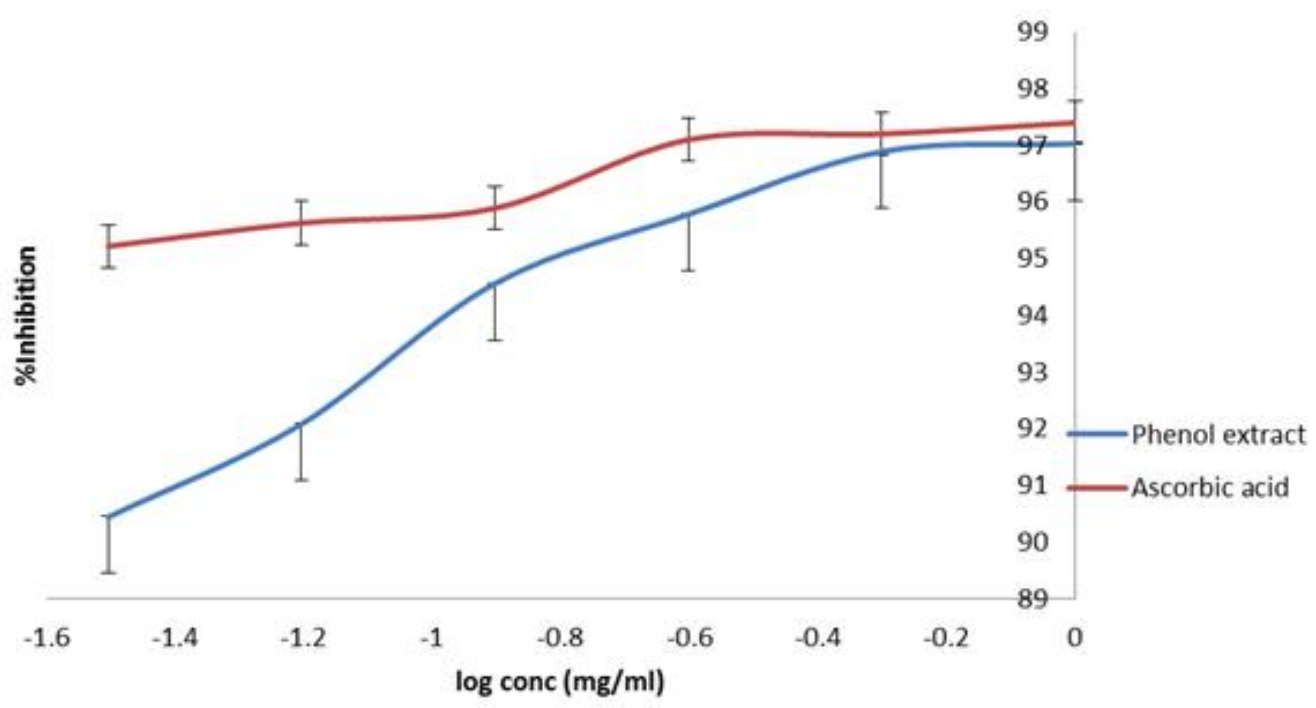

Figure 6 : Antioxidant activity of phenol extract with ascorbic acid

\section{Discussion}

Phytochemicals are non-nutritive plant chemicals that have protective (or) diseases preventive properties. Plant produces these chemicals to protect itself but recent research demonstrates that many phytochemicals can protect humans against diseases (19). The phytochemical analysis of phenol extract of P.biglobosa showed the presence of phenols and tannins, studies indicated the presence of phenols and tannins in P.biglobosa $[12,20]$.Thin layer chromatography studies showed the confirmation of phenolic compounds like tannins and phenols $R_{f} 0.78$ and 0.97 values which were more close to the standards $R_{f} 0.78$ and 0.97 values with prominent bluish green coloration. Prominent $\mathrm{O}-\mathrm{H}$ stretching confirms the presence of phenolic compound in P.biglobosa, the phenolic compounds have rings of phenols, double bond conjugation system and aldehyde or ketone groups.

There was no mortality in animals at all doses of the compound up to $500 \mathrm{mg} / \mathrm{ml}$. The absence of death at doses up to $500 \mathrm{mg}$ extract $/ \mathrm{kg}$ showed that LD50 of the NBA is greater than $500 \mathrm{mg} / \mathrm{kg}$ P.O. Toxicological studies on the crude extract had already been conducted by Builders et al [21], this will go a long way to specify the parameters necessary to the development of a drug.

The phenol extract elicited potent activity against the rodent malaria parasite used in this study, the extract also exhibited very good antiplasmodial activity against the clinical isolate of P.falciparum. The results of this study suggest that the phenol extract has potential value in the treatment of malaria. Many secondary metabolites of plants' origin have been shown to have antiplasmodial activity [22], The antiplasmodial activities of many phenolic compounds had been described by Laphookhieo et al [23] and Kusch et al [24].

African locust bean tree is used prominently as food and medicine by many traditional medicine practitioners in Nigeria e.g. The stem bark and leaf of African locust bean tree are used traditionally for the treatment of malaria $[4,25]$. In vivo and in vitro antiplasmodial activities of leaves of P.biglobosa had already been evaluated by Builders et al [12], studies on the efficacy of the stem bark of this important medicinal plant had already been reported by Builders et al [20], and also anti-inflammatory and analgesic activities of this plant had been reported by Kouadio et al [26].

Studies carried out by Milligo-Kone et al [27] indicated that the stem bark of P.biglobosa possessed antioxidant activities which might be attributed to the phenolic composition of the plant. Regarding the mechanism of action of phenol extract, our attention was focused on antioxidant activity. The presence of phenolic compounds in the plant is likely to be responsible for the free radical scavenging effects observed. Phenolic compounds are tannins and plant phenolics are a major group of compounds that act as primary antioxidants or free radicals scavengers [28]. The antioxidant activity of phenolic compounds is mainly due to their redox properties, which can play an important role in adsorbing and neutralising free radicals, quenching singlet and triplet oxygen, or decomposing peroxides [23].

The antioxidant phenolic compounds have also been shown to exert antiplasmodial activity by elevating the red blood cell oxidation and inhibiting the parasite's protein synthesis and also counteract the oxidative damage induced by the malaria parasite [5]. Thus, the antioxidant activities of this compound may represent another mechanism that contributes to its antiplasmodial activity. 


\section{Conclusion}

Phenolic compounds were found to be the major antimalarial componens of P.biglobosa. Phenolic compounds account for most of the in vivo and in vitro antiplasmodial effect of this plant. Antioxidant activity may represent mechanism that contributes to its anti-malarial activity. This justifies the use of stem bark of P.biglobosa in Nigerian folk medicine for the treatment of malaria. Further investigation, including the identification of chemical structures of these compounds is likely to yield new anti-malarial drug candidates.

\section{Acknowledgement}

We would like to thank Professors Abayomi Orishadipe and the National Institute for Pharmaceutical Research and Development [NIPRD], Idu Industrial area, Abuja, Nigeria.for their help and technical assistance.

\section{References}

[1]. World health statistics annual. Geneva: WHO 1992; p.17: 349.

[2]. Htut, Z.W. Artemisinin resistance in Plasmodium falciparum malaria. England Journal of Medicine, 361, $2009,1807-1808$.

[3]. Sendagire H, Kyabayinze D, Swedberg G, Kironde, F. Plasmodium falciparum: Higher incidence of molecular resistance markers for sulfadoxine than for pyrimethamine in Kasangati, Uganda. Tropical Medicine International Health., 10, 2005, 537-543.

[4]. Asase A, Oteng-Yeboah A.A, Odamtten G.T, Simmonds, M.S. Ethnobotanical study of some Ghanaian antimalarial plant. Journal of Ethnopharmacology, 99, 2005, 273-279.

[5]. Builders, M.I, Wannang, N.N, Ajoku, G.A, Builders, P.F, Orisadipe, A, Aguiyi, J.C. Evaluation of antimalarial potential of Vernonia ambigua Kotschy and Peyr (Asteraceae). International Journal of Pharmacology, 18(11), 2010, 1-9.

[6]. [Wagner, H, Bladt, S. Plant drug analysis in a thin layer chromatograophy Atlas (2nd Ed) (New Delhi: Thomson Press Ltd, 2004).

[7]. Shriner, R, Fuson, R, Curtin, D, Morrill, T. The systematic identification of organic compounds. ( $6^{\text {th }}$ Ed), (USA: John Wiley and Sons, 1979).

[8]. Ayoola, G.A, Coker, H.A, Adesegun, S.A, Adepoju-Bello, A.A, Obaweya, K, Ezennia, E.C, Atangbayila, T.O. Phytochemical screening and antioxidant activities of some selected medicinal plant used for malaria therapy in South western Nigeria. Tropical Journal of Pharmaceutical Research , 7, 2008, 1019-24.

[9]. ENV/MC/CHEM. OECD series on principles of good laboratory practice and compliance monitoring number 1. OECD Principles on good laboratory practice (as revised in 1997). Environment Directorate Organization for Economic Co-operation and Development Paris, 1998. Available from: http://www.iris-pharma.com/download/Principles-on-GLP.pdf , accessed 20-Oct-2012.

[10]. NIH Publication No. 85-23, (1985). Respect for life. National Institute of Environmental Health Sciences-NIEHS. http://www.niehs.nih.gov/oc/factsheets/wrl/studybgn.htm.

[11]. Lorke, D. A new approach for acute toxicity testing. Arch toxicology. 54, 1983, 275-287.

[12]. Builders, M, Wannang, N, Aguiyi, J. Antiplasmodial activities of Parkia biglobosa leaves:In vivo and In vitro studies. Annals of Biological Research. 2 (4), 2011, 8-20.

[13]. Peters, W, Robinson B.L. The chemotherapy of rodent malaria XLVII: studies on pyronaridine and other Mannich base antimalarials. Annals of Tropical Medicine and Parasitology. 86, 1992, 455-465.

[14]. Saidu, K, Onah, J, Orisadipe, A, Olusola, A, Wambebe, C, Gamaniel, K. Antiplasmodial, analgesic, and anti-inflammatory activities of the aqueous extract of Erythrina senegalensis. Journal of Ethnopharmacology. 71, 2007, 275-280.

[15]. Peters, W. Drug resistance in Plasmodium berghei. Vinke and Lips 1948. I. Chloroquine resistance. Experimental Parasitology. $17,1965,80-89$.

[16]. Hilou, A, Nacoulma, O.G, Guiguemde, T.R. Antimalarial activities of extracts from Amaranthus spinosus, Boerhaavia erecta L. in mice. Journal of Ethnopharmacology. 103, 2006, 236-240.

[17]. In vitro micro test (MarkIII) for the assessment of the response of Plasmodium falciparum to chloroquine, mefloquine, quinine, amodiaquine, sulfadoxine/pyrimethamine and artemisinin. CTD/MAL/97, 20. Geneva: WHO; 2001.

[18]. Alshawsh, S.M, Mothana, RA, Al-Shamahy, H.A, Alsllami, S.F, Lindequist, U. Assessment of antimalarial activity against Plasmodium falciparum and phytochemical screening of some Yemeni medicinal plants. Evidence- Based Complementary Alternative Medicine 2007; 6: 453-456.

[19]. Rajan, T, Muthukrishinana, S. Characterization of phenolic compounds in Pseudaarthria viscida a root extract by HPLC and FTIR analysis. Asian Journal of Pharmaceutical and Clinical Research 6, 2013, Suppl 2,

[20]. Builders, M.I , Tarfa, F, Aguiyi, J.C. The potency of African locust bean tree as an antimalarial. Journal of Pharmacology and Toxicology . 7, 2012, 274-287.

[21]. Builders, M.I, Isichie, C.O, Aguiyi, J.C. Toxicity studies of the extracts of Parkia biglobosa stem bark in rats. British Journal of Pharmaceutical Research. 2, 2012, 1-16.

[22]. Saxena, S, Pant, N, Jain, D.C, Bhakuni, R.S. Antimalarial agents from plant sources. Current Science. 9, 2003 , 1314-1329.

[23]. Laphookhieo, S, Maneerat, W, Koysomboon, S. Antimalarial and cytotoxic phenolic compounds from Cratoxylum maingayi and Cratoxylum cochinchinense. Molecule. 14, 2009, 1389-1395.

[24]. Kusch, P, Deinninger, S, Specht, S, Maniako, R, Haubrich, S, Pommerening, T, Lin, P, Hoerauf, A, Kaiser, A. In vitro and in vivo antimalarial activity assays of seeds from Balanites aegyptiaca: compounds of the extract show growth inhibition and activity against Plasmodial aminopeptidase. Journal of Parasitology Research. 2011, 2007, 1-9.

[25]. Gronhaug, T.E, Glaeserud, S, Skogsrud, M, Ballo, N, Bah, S, Diallo, D, Paulsen, BS. Ethnopharmacological survey of six medicinal plants from Mali, West Africa. Journal of Ethnopharmacology. 4, 2008, 4-26.

[26]. Kouadio, F, Kanko, C, Juge, M, Grimaud, N, Jean, A, N'Guessan, Y.T, Petit, J.Y. Analgesic and antiinflammatory activities of an extract from Parkia biglobosa used in traditional medicine in the Ivory Coast. Phytotherapy Research.. 14, 2000, 635-637.

[27]. Millogo, H, Lompo, M, Kini, F, Asimi, S, Guissou, I.P, Naucoulma, O . Evaluation of flavonoids and total phenolics content of stem bark and leaves of P.biglobosa (Jacq) Benth (Mimosaceae), free radical scavenging and antimicrobial activities. Phytotherapy Research. 8, 2000, 635-642.

[28]. Kim, K, Lee, S, Jung, S, Park, H, Shinkilt, Y, Kim, B.K. Anti oxidant activities of the extracts from the herbs of Artemisia apiacea. Journal of Ethnopharmacology. 85, 2003, 69-72. 